\title{
Rock-protecting Seaweed? Experimental evidence of bioprotection in the intertidal zone
}

\author{
Matthew R. Gowell ${ }^{1}$ \\ Martin A. Coombes ${ }^{1 *}$ \\ Heather A. Viles ${ }^{1}$ \\ ${ }^{1}$ Oxford Rock Breakdown Laboratory, School of Geography and the Environment, University \\ of Oxford, South Parks Road, Oxford OX1 3QY \\ ${ }^{*}$ Corresponding author: Martin.Coombes@ouce.ox.ac.uk
}

\begin{abstract}
Biogeomorphological processes are an important component of dynamic intertidal systems. On rocky shores, the direct contribution of microorganisms, plants and animals to weathering and erosion is well known. There is also increasing evidence that organisms can alter rock breakdown indirectly, by moderating temperature and moisture regimes at the rock-air interface. These influences have been purported to represent mechanisms of bioprotection, by buffering microclimatic fluctuations associated with weathering processes such as wetting and drying and salt crystallisation. However, virtually nothing has been done to test whether microclimatic buffering translates to differences in actual rock breakdown rates.

Here we report a preliminary laboratory experiment to assess how an artificial canopy (chosen to represent seaweed) affects mechanical rock breakdown. Using a simplified and accelerated thermal regime based on field data from on a rocky shore platform in southern England, UK, we find that breakdown (mineral debris release) of mudstone covered with a canopy is reduced by as much as $79 \%$ relative to bare rock after around 100 thermal cycles. Reduction in rock surface hardness (measured using an Equotip device) was also greater for bare rock $(17 \%)$ compared to covered rock $(10 \%)$ over this period. Measurements of salt crystal formation indicate that the mechanism driving these differences was a reduction in the frequency of crystallisation events, via moisture retention and shading of the rock surface.
\end{abstract}

Key Words: biogeomorphology, bioprotection, rocky shore platform, weathering, rock breakdown, salt crystallization 


\section{Introduction}

The roles of organisms (microorganisms, plants and animals) in geomorphology are increasingly recognised in a range of environments across a broad spectrum of spatial and temporal scales (Reinhardt et al., 2010; Corenblit et al., 2011; Butler and Sawyer, 2012). This includes the intertidal zone where bioerosion is known to play a role in the development of rock landforms and landscapes (e.g. Naylor et al., 2012). However, proportionally very little work has been done on the possible protective roles of organisms with respect to rock breakdown (termed 'bioprotection', see Carter and Viles, 2005).

In the built environment, microclimatic data have been used to infer a bioprotective role for vegetation canopies with respect to stone decay, via thermal buffering and protection from damaging frosts for example (Sternberg et al., 2011; Viles et al., 2011a). In the intertidal zone, where weathering is dominated by tidal inundation and salts (Mottershead, 2013; Coombes, 2014), marine macroalgae (seaweed) canopies have similarly been found to reduce the magnitude and frequency of across-tide (diurnal) and between-tide (minutes to hours) fluctuations in rock-surface microclimate (Coombes et al., 2013a). Based on this work it was hypothesised that seaweed canopies may reduce the rate of rock breakdown by decreasing the efficiency of mechanical weathering processes, namely wetting and drying, warming and cooling, and the frequency of salt crystallisation during periods of low tide. While Coombes et al. (2013a) provide evidence of the mechanisms by which this mode of bioprotection may occur (i.e. thermal buffering and water retention), as yet there is no direct evidence of whether these effects influence actual rock breakdown rates. In order to test this, we developed a simple laboratory-based experiment to assess the influence of an artificial canopy on rock mineral debris loss, salt crystallisation and hardness change under an accelerated weathering regime.

\section{Methodology}

\section{Rock samples}

Samples of rock were obtained from the same bed of a shore platform at Croyde Bay, North Devon, UK $\left(51^{\circ} 08^{\prime} 01.80^{\prime \prime} \mathrm{N}, 4^{\circ} 14^{\prime} 26.28^{\prime \prime} \mathrm{W}\right)$ (Figure 1). The platform is comprised of mudstone from the Pilton Mudstone Formation, of Upper Devonian (Famennian) age (Whittaker and Leveridge, 2011). Uniformly-sized sample blocks (50 mm x $50 \mathrm{~mm}$ x $30 \mathrm{~mm}$ ) were cut from the platform material such that five faces were freshly cut and one face (the test surface) was pre-weathered. The use of pre-weathered samples in laboratory weathering experiments has been previously advocated (Mottershead, 1982; Warke and Smith, 2007). The five cut faces of each block were coated in polyurethane varnish to ensure that the exchange of moisture and salts could only occur through the remaining unvarnished face (Smith and McGreevy, 1983). This procedure is thought to better replicate in situ rock masses (Smith et al., 2005; Coombes, 2011). The prepared blocks were then washed in distilled water to remove any loose debris from cutting, oven dried for 24 hours at $105^{\circ} \mathrm{C}$, and their initial dry weight determined. For this preliminary study, six prepared blocks were subjected to an 
accelerated tidal weathering regime (outlined below) and an additional two blocks were stored in ambient laboratory conditions as controls.

\section{Weathering simulation}

The procedure used to simulate tidal conditions in the laboratory is shown schematically in Figure 2. The six prepared blocks were immersed in an artificial seawater solution (Tropic Marin ${ }^{\circledR}$ ) of salts (35 parts per thousand) and trace elements for three hours, representing tidal inundation. These blocks were repeatedly re-immersed (the 'wetting phase' in Figure 2) every three days, for the same period of time, over the course of the experiment (a total of 12 immersions). Between wetting phases, blocks were subjected to an accelerated climatic regime (the 'drying phase' in Figure 2) in an environmental chamber (Binder KBF115) (Figure 3a).

Following the approach used to assess the influence of other intertidal organisms on rock thermal regimes (e.g. Coombes, 2011; Coombes and Naylor, 2012; Coombes et al., 2014), the chamber was programmed to simulate conditions representative of those occurring in the field. Based on monitoring on the platform at Croyde Bay during summer 2012, a constant relative humidity of $80 \%$ was adopted for the simulation. The peak rock-surface temperature recorded during the same summer was $+40^{\circ} \mathrm{C}$, adopted as the upper value for the simulation. The average minimum temperature across several years for the month of January $\left(+3^{\circ} \mathrm{C}\right)$ was adopted as the lower simulated value, as determined from meteorological data for the nearest climate station at Chivenor (UK Met Office). The simulated thermal cycle therefore consisted of a warming period from $+3^{\circ} \mathrm{C}$ to $+40^{\circ} \mathrm{C}$ over 4 hours, followed by a cooling period from $+40^{\circ} \mathrm{C}$ to $+3^{\circ} \mathrm{C}$ over the following 4 hours (Figure $3 \mathrm{~b}$ ). This cycle was continuously repeated (i.e. 3 cycles every 24 hours) giving roughly 105 full cycles over the 5 week experiment. This approach represents a simplified and accelerated temperature cycle within the bounds of annual meteorological conditions occurring on a temperate rocky shore, in a year with a relatively hot summer. The potential for mechanical rock breakdown on temperate intertidal platforms is thought to be greatest under hot summer conditions, when the efficiency of rock warming and drying during low tides will be greatest (Coombes, 2014).

In addition to ambient thermal cycling in the cabinet, blocks were directly heated using a lamp. Radiant heating in this way replicates the warming of rock via insolation-as occurs in the field - much better as temperatures are determined both by the thermal properties of the rock as well as the air (Warke and Smith, 1998; Smith et al., 2005). The lamp was set to switch on and off at 15-minute intervals using an automatic timer, simulating short-term variability in heating that occurs in the field when rock and stone surfaces are exposed to the air during the day (e.g. Jenkins and Smith, 1990) (Figure 3a). At low tide on rocky shores, thermal variability over these timescales occurs as a function of wind gusts and interruptions to insolation by passing cloud (Coombes, 2011).

During simulation phases in the cabinet, the blocks were embedded in expanded polystyrene. This was to further ensure conditions were as representative of larger rock masses as far as possible, by minimising edge effects and concentrating thermal exchange through the upper 
weathered face (McGreevy, 1985; Carter and Viles, 2003; Smith et al., 2005; Coombes, 2011). To test the influence of canopy cover on breakdown rates, three of the blocks were covered by an artificial 'seaweed canopy' and three blocks were left uncovered (Figure 3c). The canopy consisted of 50 strips $(1 \mathrm{~cm} \mathrm{x} 14 \mathrm{~cm})$ of chemically inert black foam, which resolved the impracticality of using live seaweed in the cabinet. Simple drying experiments showed that the foam had comparable water-holding properties to real seaweed blades, and as such was deemed a suitable practical substitute. Seaweed forms thick canopies on most lower rocky shore surfaces (as well as on hard engineered structures) with dominant species and density largely dependent on tidal height and prevailing wave conditions. Whilst we did not aim to simulate a specific species, this set-up represents two extremes of a spectrum of canopy cover - no cover (bare rock) and completely covered rock (Figure 3c).

Hygrochron and Thermochron iButton ${ }^{\circledR}$ loggers were positioned in the cabinet, adjacent to both bare and 'colonised' blocks, for the duration of the experiment to record near-surface microclimate at 1-minute intervals. The iButtons were covered in aluminium foil to prevent direct heating of the metal components of the loggers (Carter and Viles, 2003; Coombes, 2011).

\section{Rock breakdown}

As a direct measure of rock breakdown, debris was collected from each block cumulatively at weekly intervals (including controls) by brushing the surface with a soft brush over white paper. This was done prior to the re-immersion of the blocks in seawater solution, before each wetting phase (Figure 2). Debris was carefully transferred to plastic weighing boats and dried at $60^{\circ} \mathrm{C}$ for 24 hours prior to weighing. To distinguish between mineral debris and crystallised salts, the dried debris was subsequently soaked in $50 \mathrm{ml}$ of distilled water and shaken periodically for three hours. Samples were then centrifuged at 3,000 rps for 15 minutes, to separate mineral debris from the solution (containing any dissolved salt), which was carefully siphoned off using a pipette (after Smith and McGreevy, 1983). The remaining debris was then re-dried and re-weighed. This method allowed the mass of mineral rock debris to be determined as a direct measure of breakdown alongside the mass of salts, as a measure of the intensity/frequency of crystallisation occurring at the rock surface.

As a further indicator of breakdown, the surface hardness of all sample blocks was determined before and after the simulation (dried to constant weight in each case). Changes in rock hardness measured using impact-rebound devices are thought to reflect often finescale $(<\mathrm{mm})$ chemical and mechanical alteration of constituent minerals and bonding agents occurring during the weathering process (Goudie, 2006; Aoki and Matsukura, 2007). For these measurements we used an Equotip (Piccolo type, Proceq) given its sensitivity to hardness variations in the uppermost layers of rock (Viles et al., 2011b; Coombes et al., 2013b). Before and after the simulation, 90 equally-spaced measurements were made across the entire surface of each block face (excluding the outer $0.5 \mathrm{~mm}$ to avoid edge effects). Paired t-tests were used to test for changes in the hardness of each block before and after the experiment. Data were checked for normality and homogeneity of variance using a Shapiro- 
Wilk test and Levene's test, respectively, and data were transformed where appropriate. All tests were carried out using Sigmaplot ${ }^{\circledR}$ computer software.

\section{Results and discussion}

The influence of canopy cover on rock-surface microclimates

Figure 4 shows near-surface temperature data for bare and 'colonised' blocks over a representative $24 \mathrm{hr}$ period. Near-surface conditions reflected the programmed thermal regime well, with clearly-defined cycles of warming and cooling. Superimposed upon this, the influence of direct warming from the lamp is indicated by the saw-tooth temperature curves, most noticeable for bare blocks during cooling phases (Figure 4); short-term thermal fluctuations were comparatively dampened for 'colonised' blocks. The covered rock samples remained cooler over the majority of the experimental run, with noticeably lower thermal peaks, in the order of $3-4{ }^{\circ} \mathrm{C}$ cooler (Figure 4). This reflects canopy shading effects, moisture retention and probable enhanced evaporative cooling relative to the bare samples that dried out quickly. Observations in the field show that bare rock dries out more frequently and more quickly than algae-covered rock (Coombes et al., 2013a), indicating that our use of an artificial canopy was an effective means of simulating these effects in the laboratory.

Relatively humidity was recorded during the experiment, but the covered loggers were subject to instrumental error owing to the consistently wet conditions under the artificial canopy. Nevertheless, the frequency and magnitude of short-term fluctuations in relative humidity were dampened under the canopy, and humidity values were always higher (by about $20-30 \%$ ) relative to the bare samples.

\section{The influence of canopy cover on mineral and salt debris}

The weekly mass of mineral debris and salt collected from the surfaces of blocks during the experiment is shown in Figure 5. Given the small number of samples employed in this preliminary experiment we have chosen not to apply statistical tests to these data. A measurable reduction in the breakdown rate of covered blocks was, nevertheless, observed; debris loss was consistently lower for blocks when covered with a canopy compared to bare blocks, particularly during the first two weeks of the experiment. At the end of the 5-week simulation, a total of $0.038 \pm 0.010 \mathrm{~g}$ of mineral debris had been collected from the bare blocks compared to $0.008 \pm 0.001 \mathrm{~g}$ from the covered blocks, an overall difference of $0.03 \mathrm{~g}$ (79\%). For the control blocks, which were not exposed to accelerated weathering conditions, total loss was negligible (Figure 5).

Concurrent measurement of salt crystal formation help identify the mechanism by which these differences mineral breakdown rates occur; more salt was collected from the bare samples $(0.018 \pm 0.004 \mathrm{~g}$ in total $)$ compared to the 'colonised' $(0.005 \pm 0.001 \mathrm{~g})$ and control $(<0.000 \pm 0.000 \mathrm{~g})$ blocks. This is taken to reflect a reduction in the frequency and extent of rock drying under the canopy, and thus the likelihood of salt crystallisation occurring. In 
contrast, visual observations indicated that the bare blocks became sufficiently dry for salt crystals to form during each drying phase.

\section{The influence of canopy cover on rock surface hardness}

Figure 6 shows mean rock surface hardness for the three experimental treatments (control, bare, and covered) before and after the simulation. Rock surface hardness decreased for every block exposed to the accelerated weathering cycle (paired t-test $p \leq 0.001$ in all cases), while differences in the hardness of control blocks were not significant (Figure 6). Observed hardness change for the cabinet blocks can therefore be attributed to weathering during the simulation rather than an artefact of sampling and time alone. Overall, the surface hardness of bare samples was reduced by $17 \%$ compared to $10 \%$ for the 'colonised' blocks, and $0.9 \%$ for the control blocks (Figure 7).

\section{Significance for weathering on rocky coasts}

As well as reducing the frequency of damaging salt crystallisation, our experimental results indicate that canopy-forming algae may protect rock by buffering fluctuations in moisture. Our observations of dampened changes in rock-surface relative humidity and reduced drying under canopies via the retention of moisture support this. This is of particular significance for intertidal landforms composed of argillaceous rock (including mudstone used here) that are subject to repeated swelling and shrinking in response to tidal wetting and drying (Stephenson and Kirk, 2001; Kanyaya and Trenhaile, 2005; Trenhaile, 2006; Porter and Trenhaile, 2007; Doostmohammadi et al., 2009; Porter et al., 2010; Zhang et al., 2010). Dampened expansion and contraction in association with temperature fluctuations (i.e. thermal fatigue effects, Hall and Thorn, 2014) may also represent a protective mechanism on algae-covered rocky shores (e.g. Hemmingsen et al., 2007; Coombes et al., 2013a). The geomorphological significance of algae bioprotection for rocky shore platforms, with respect to topographic change and progressive reductions of mass strength, will be greatest for those comprising vulnerable lithologies like mudstone (e.g. Stephenson and Kirk, 2000). Our preliminary data provide the first quantitative evidence of previously implied mechanisms by which algal canopies probably limit rock breakdown, by retaining moisture, buffering swelling and shrinking cycles, and reducing the frequency of salt crystallisation relative to bare rock. A reduction in the rate of hardness loss of 'colonised' rock samples demonstrates these effects alongside direct measures of mass loss.

\section{Conclusion}

Using an accelerated weathering experiment simulating temperate summertime conditions, we found that an artificial canopy reduced the amount of mineral debris release from mudstone in comparison to bare rock over a five week period (representing around 105 tidal cycles). Our data indicate that buffering of warming/drying cycles by canopy-forming seaweed has two important implications with respect to mechanical modes of rock breakdown. First, dampened microclimatic fluctuations under dense canopies provides a 
mechanism by which swelling and shrinking in association with wetting and drying are limited and, second, by which the frequency of salt crystallisation events is reduced via moisture retention. The greater amounts of salts collected from the surfaces of bare rock samples provide strong evidence for this as an indirect (i.e. passive) bioprotective mechanism. Furthermore, while hardness loss was significant for all samples over the course the experiment (Figure 6), the magnitude of change was consistently reduced when covered with an artificial canopy. These observations add to previous suggestions that seaweeds can play a bioprotective role on rocky shores (Stephenson and Kirk, 2000; Moura et al., 2012; Coombes et al., 2013a), offering the first laboratory-based experimental evidence of lower breakdown rates and of the mechanism by which this occurs.

Whilst our data demonstrate how moisture retention by canopy-forming species is probably protective with respect to salt crystallisation, the influence of these effects on chemical weathering requires further investigation. The nature of other biological weathering and erosion processes may also be affected by canopy cover, by altering the abundance of microbial biofilms and bioeroders such as limpets and snails for example (Bertness et al., 1999; Hutchinson et al., 2006; Wikström and Kautsky, 2007), but this remains to be investigated in any great detail. The relative importance of bioprotection under different tidal regimes and thermal regimes would prove a particularly interesting area of future study, as microclimatic buffering may well be greatest in hotter climates where wetting and drying cycles are more pronounced (Stephenson et al. 2013; Coombes, 2014). On the other hand, buffering of very cold conditions (i.e. frosts) may too be important under certain climatic regimes (e.g. Trenhaile, 2014). Laboratory based experiments similar to the one we have described offer great promise here, particularly if coupled with field-based monitoring. Rock properties such as thermal capacity, porosity and strength (McGreevy, 1985; Sunamura, 1994) will no doubt have some bearing on the efficiency and importance of bioprotection (not only by seaweed but other species too) and this needs to be looked at in more detail. Lastly, the influence of factors controlling the density of plants and canopy thickness on rocky shores (including tidal height, wave exposure and disturbance, and species morphological traits) need to be considered more in a biogeomorphological context, as we believe biomass will be a particularly strong predictor of bioprotective potential in a range of settings. 


\section{References}

Aoki H, Matsukura Y. 2007. A new technique for non-destructive field measurement of rock-surface strength: an application of the Equotip hardness tester to weathering studies. Earth Surface Processes and Landforms 32: 1759-1769

Bertness MD, Leonard GH, Levine JM, Schmidt PR, Ingraham AO. 1999. Testing the relative contribution of positive and negative interactions in rocky intertidal communities. Ecology $\mathbf{8 0}$ 2711-2726

Butler DR, Sawyer CF. 2012. Special Issue Zoogeomorphology and Ecosystem Engineering Proceedings of the 42nd Binghamton Symposium in Geomorphology. Geomorphology 157158: 1-192

Carter NEA, Viles HA. 2003. Experimental investigations into the interactions between moisture, rock surface temperatures and an epilithic lichen cover in the bioprotection of limestone. Building and Environment 38: 1225-1234

Carter NEA, Viles HA. 2005. Bioprotection explored: the story of a little known earth surface process. Geomorphology 67: 273-281

Coombes MA. 2011. Rock warming and drying under simulated intertidal conditions, part I: experimental procedures and comparisons with field data. Earth Surface Processes and Landforms 36: 2114-2121.

Coombes MA. 2014. The rock coast of the British Isles: weathering and biogenic processes. In Rock Coast Geomorphology: A Global Synthesis, Kennedy D, Stephenson W, Naylor L (eds). Geological Society of London Memoirs 40: London; 57-76.

Coombes MA, Naylor LA. 2012. Rock warming and drying under simulated intertidal conditions, part II: weathering and biological influences on evaporative cooling and near-surface micro-climatic conditions as an example of biogeomorphic ecosystem engineering. Earth Surface Processes and Landforms 37: 100-118.

Coombes MA, Naylor LA, Viles HA, Thompson RC. 2013a. Bioprotection and disturbance: Seaweed, microclimatic stability and conditions for mechanical weathering in the intertidal zone. Geomorphology 202: 4-14.

Coombes MA, Feal-Pérez A, Naylor LA, Wilhelm K. 2013b. A non-destructive tool for detecting changes in the hardness of engineering materials: Application of the Equotip durometer in the coastal zone. Engineering Geology 167: 14-19.

Coombes MA, Viles H, Naylor L. 2014. Biological influences on internal stone temperatures: laboratory procedures and preliminary results for intertidal barnacles. Proceedings of the 12th International Conference on the Deterioration and Conservation of Stone, Columbia University, New York. Available at http://iscs.icomos.org/pdffiles/NewYorkConf/coometal.pdf, accessed 11/12/2014.

Corenblit D, Baas ACW, Bornette G, Darrozes J, Delmotte S, Francis RA, Gurnell AM, Julien F, Naiman RJ, Steiger J. 2011. Feedbacks between geomorphology and biota controlling Earth surface processes and landforms: A review of foundation concepts and current understandings. EarthScience Reviews 106: 307-331

Doostmohammadi R, Moosavi M, Mutschler T, Osan C. 2009. Influence of cyclic wetting and drying on swelling behavior of mudstone in south west of Iran. Environmental Geology 58: 999-1009.

Goudie AS. 2006. The Schmidt Hammer in geomorphological research. Progress in Physical Geography 30: 703-718 
Hall K, Thorn CE. 2014. Thermal fatigue and thermal shock in bedrock: An attempt to unravel the geomorphic processes and products. Geomorphology 206: 1-13.

Hemmingsen SA, Eikaas HS, Hemmingsen MA. 2007. The influence of seasonal and local weather conditions on rock surface changes on the shore platform at Kaikoura Peninsula, South Island, New Zealand. Geomorphology 87: 239-249.

Hutchinson N, Nagarkar S, Aitchison JC, Williams GA. 2006. Microspatial variation in marine biofilm abundance on intertidal rock surfaces. Aquatic Microbial Ecology 42: 187-197

Jenkins KA, Smith BJ. 1990. Daytime rock surface temperature variability and its implications for mechanical rock weathering: Tenerife, Canary Islands. Catena 17: 449-459.

Kanyaya JI, Trenhaile AS. 2005. Tidal wetting and drying on shore platforms: An experimental assessment. Geomorphology 70: 129-146.

McGreevy JP. 1985. Thermal rock properties as controls on rock surface temperature maxima, and possible implications for rock weathering. Earth Surface Processes and Landforms 10: 125-136

Mottershead DN. 1982. Rapid weathering of greenschist by coastal salt spray, east Prawle, South Devon: a preliminary report. Proceedings of the Ussher Society 5: 347-353

Mottershead DN. 2013. Coastal Weathering. In Treatise on Geomorphology Volume 4, Weathering and Soils Geomorphology., John F. Shroder (Editor-in-chief) P, G.A. (Volume Editor) (ed). Academic Press: San Diego; 228-244.

Moura D, Gabriel S, Gamito S, Santos R, Zugasti E, Naylor L, Gomes A, Tavares AM, Martins AL. 2012. Integrated assessment of bioerosion, biocover and downwearing rates of carbonate rock shore platforms in southern Portugal. Continental Shelf Research 38: 79-88.

Naylor LA, Coombes MA, Viles HA. 2012. Reconceptualising the role of organisms in the erosion of rock coasts: A new model. Geomorphology 157-158: 17-30.

Porter NJ, Trenhaile AS. 2007. Short-term rock surface expansion and contraction in the intertidal zone. Earth Surface Processes and Landforms 32: 1379-1397.

Porter NJ, Trenhaile AS, Prestanski K, Kanyaya JI. 2010. Patterns of surface downwearing on shore platforms in eastern Canada. Earth Surface Processes and Landforms 35: 1793-1810.

Reinhardt L, Jermlmack D, Cardinale BJ, Vanacker V, Wright JP. 2010. Dynamic interactions of life and its landscape: feedbacks at the interface of geomorphology and ecology. Earth Surface Processes and Landforms 35: 78-101

Smith BJ, McGreevy JP. 1983. A simulation study of salt weathering in hot deserts. Geografiska Annaler A 64: 127-133

Smith BJ, Warke PA, McGreevy JP, Kane HL. 2005. Salt weathering simulations under hot desert conditions: agents of enlightenment or perpetuators of preconceptions? Geomorphology 67: 211-227

Stephenson WJ, Kirk RM. 2000. Development of shore platforms on Kaikoura Peninsula, South Island, New Zealand: Part II: The role of subaerial weathering. Geomorphology 32: 43-56

Stephenson WJ, Kirk RM. 2001. Surface swelling of coastal bedrock on inter-tidal shore platforms, Kaikoura Peninsula, South Island, New Zealand. Geomorphology 41: 5-21.

Stephenson WJ, Dickson ME, Trenhaile AS. 2013. Rock coasts. In Treatise on Geomorphology vol. 10, Coastal Geomorphology, Shroder J (ed-in-chief), Sherman D (ed). Academic Press: San Diego, CA; 289-307.

Sternberg T, Viles H, Cathersides A. 2011. Evaluating the role of ivy (Hedera helix) in moderating wall surface microclimates and contributing to the bioprotection of historic buildings. Building and Environment 46: 293-297. 
Sunamura T. 1994. Rock control in coastal geomorphic processes. Transactions of the Japanese Geomorphological Union 15: 253-272

Trenhaile AS. 2006. Tidal wetting and drying on shore platforms: An experimental study of surface expansion and contraction. Geomorphology 76: 316-331.

Trenhaile AS. 2014. The rock coast of Canada. In Rock Coast Geomorphology: A Global Synthesis, Kennedy D, Stephenson W, Naylor L (eds). Geological Society of London Memoirs 40: London; 125-136.

Viles HA, Sternberg T, Cathersides A. 2011a. Is ivy good or bad for historic walls? Journal of Architectural Conservation 17: 25-41

Viles H, Goudie A, Grab S, Lalley J. 2011b. The use of the Schmidt Hammer and Equotip for rock hardness assessment in geomorphology and heritage science: a comparative analysis. Earth Surface Processes and Landforms 36: 320-333.

Warke PA, Smith BJ. 1998. Effects of direct and indirect heating on the validity of rock weathering simulation studies and durability tests. Geomorphology 22: 347-357

Warke PA, Smith BJ. 2007. Complex weathering effects on durability characteristics of building stone. Geological Society of London, Special Publications 271: 211-224

Whittaker A, Leveridge BE. 2011. The North Devon Basin: a Devonian passive margin shelf succession. Proceedings of the Geologists' Association 122: 718-744.

Wikström SA, Kautsky L. 2007. Structure and diversity of invertebrate communities in the presence and absence of canopy-forming Fucus vesiculosus in the Baltic Sea. Estuarine, Coastal and Shelf Science 72: 168-176.

Zhang CL, Wieczorek K, Xie ML. 2010. Swelling experiments on mudstones. Journal of Rock Mechanics and Geotechnical Engineering 2: 44-51 


\section{Figure Captions:}

\section{Fig. 1.}

Location of Croyde Bay, North Devon, UK.

\section{Fig. 2.}

Schematic representation of the accelerated tidal cycle simulated in the laboratory (immersion during wetting phases was in synthetic seawater and drying phases were simulated in an environmental cabinet).

\section{Fig. 3.}

Experimental procedures: (a) samples in an environmental cabinet during the 'drying phase'; (b) climate regime simulated in the environmental cabinet during drying phases; (c) sample blocks showing use of an artificial canopy for 'colonised' blocks (representing fullycolonised rock), bare blocks, and control blocks. iButton thermochrons were used to record microclimate adjacent to bare and covered (not visible) samples.

\section{Fig. 4.}

Near-surface temperature data for bare (solid line) and 'colonised' (dotted line) blocks during drying phases of the simulation.

\section{Fig. 5.}

Mean mass of mineral and salt debris collected from control, bare, and 'colonised' samples of mudstone for week of the simulation period ( $n=3$ for bare and colonised blocks, $n=2$ for controls).

\section{Fig. 6.}

Surface hardness of each sample block before and after the weathering simulation, as measured using an Equotip piccolo (mean $\pm \mathrm{SD}, n=90$, Student's t-test statistical significance as shown).

\section{Fig. 7.}

Hardness change for different experimental treatments following the simulation (mean $+\mathrm{SD}$, $n=3$ for bare and 'colonised' treatment, $n=2$ for control treatment). 